\title{
La competencia intercultural y la competencia pragmática en la enseñanza de español como lengua extranjera (ELE)
}

\section{Pragmatic competence and intercultural competence in Spanish language teaching}

\author{
Małgorzata Spychała-Wawrzyniak \\ Uniwersytet im. Adama Mickiewicza w Poznaniu (Polonia) \\ malgorzata.spychala@amu.edu.pl \\ María del Carmen Suñén Bernal \\ Leuphana Universität Lüneburg (Alemania) \\ sunen-bernal@leuphana.de
}

\begin{abstract}
The main purpose of this article is to present the development and evolution of two fundamental components of the communicative competence in the teaching of foreign languages: pragmatics and interculturality. We will analyze different visions of pragmatic competence and intercultural competence, which are sometimes treated as synonymous concepts. We will focus our attention on the problems observed in class as a consequence of the great diversity of cultural contexts in which Spanish is learned, highlighting the importance of activating the development of both competences in class and the need to learn to negotiate linguistic and cultural meanings within a cultural context different from that of the target language. Finally, we will present the results of a study carried out with students from a Polish and a German university, whose objective was to analyze the previous attitudes of students from different faculties towards two competences that should always go hand in hand: pragmatics and interculturality.
\end{abstract}

Keywords: communicative competence, intercultural competence, pragmatic competence, Spanish learning 


\section{INTRODUCCIÓN: LA COMUNICACIÓN INTERCULTURAL Y LA COMPETENCIA COMUNICATIVA}

La situación actual del mundo multicultural ha colocado la competencia comunicativa del estudiante de una lengua extranjera en el nuevo punto de análisis por parte de los investigadores. En el caso de la comunicación intercultural actualmente se otorga la máxima prioridad a la eficacia comunicativa entre los interlocutores provenientes de distintas culturas. Amorós Negre (2014) añade que "esto se logra con independencia del seguimiento estricto de las normas lingüísticas codificadas en diccionarios y gramáticas" (p. 16). Además, como subraya Moreno Fernández (2012, p. 21), "la lengua es variable y se manifiesta de modo variable", ya que el uso de ciertas palabras en la misma comunidad lingüística (p. ej. España, México) ${ }^{1}$ puede expresar significados y valores semánticos diferentes. Esta complejidad cultural y lingüística se ve claramente reflejada en la comunidad hispánica. Ricós Vidal (2013) recuerda que el español es un "disistema multilectal, en el que podemos observar variaciones diatópicas, distráticas y diafásicas" (p. 50) y se ha convertido en uno de los pocos idiomas internacionales con más de 450 millones de hablantes incluyendo a las personas que lo aprenden.

La cuestión que aquí se plantea es, por tanto, cómo desarrollar la competencia comunicativa de los alumnos y, sobre todo, de qué manera trabajar las cuestiones pragmáticas y culturales en la clase de ELE de forma paralela. Según el Marco común europeo de referencia (MCER, 2002, p. 10), la enseñanza y el aprendizaje de idiomas incluye varias dimensiones: las estrategias, las tareas, los textos, las competencias generales, las actividades de la lengua, los ámbitos y la competencia comunicativa. Con respeto a esta última, el MCER (2002) y el Companion Volume (Council of Europe, 2020) la dividen en tres componentes: el lingüístico, el sociolingüístico y el pragmático. El primero se basa en los conocimientos léxicos, sintácticos y fonológicos. Las competencias sociolingüísticas abarcan sobre todo las condiciones socioculturales (p. ej. la cortesía) y los conocimientos pragmáticos (p. ej. los actos de habla) que se combinan con el uso funcional de la lengua. Esta visión de la competencia comunicativa no se aleja mucho de los conceptos establecidos antes por Chomsky (1965) ${ }^{2}$, Hymes (1972) y Canale \& Swain (1980). En su modelo de la competencia comunicativa, Canale \& Swain (1980) establecen los siguientes elementos: gramatical (conocimiento del léxico y corrección formal), discursivo (cohesión de

\footnotetext{
${ }^{1}$ Moreno Fernández (2012, p. 23) explica que los hispanohablantes de México y España pertenecen a una misma comunidad lingüística de la lengua española pero no a una misma comunidad de habla, en la que los hablantes comparten también el mismo conjunto de normas y valores de naturaleza sociolingüística.

${ }^{2}$ Hay que notar que Chomsky (1957) hacía referencia especialmente a la competencia lingüística.
} 
formas y coherencia de sentido), sociolingüístico (adecuación) y estratégico (flujo de comunicación). Aunque estos autores omiten el componente pragmático, Cots (2000, p. 104) -siguiendo el modelo de Canale \& Swain (1980)- decidió unir los componentes sociolingüístico, discursivo (textual) y estratégico dentro de la competencia pragmática. Su objetivo era sobre todo "rechazar la idea de poner énfasis únicamente en actos de habla aislados o cortas rutinas comunicativas". Esta visión de la competencia pragmática pretende principalmente demostrar que es posible elaborar un modelo flexible de una competencia. En este contexto resulta interesante la propuesta del modelo de la competencia comunicativa o lingüística de Bachman (2000, p. 109), según el cual se agrupan distintos componentes bajo dos tipos de competencias: la organizativa (morfología, sintaxis, vocabulario, cohesión) y la pragmática, que incluye no solo los elementos de la competencia sociolingüística, sino también las habilidades "relacionadas con las funciones que se realizan por medio del uso de le lengua".

Las investigaciones más importantes realizadas hasta ahora en el ámbito de la competencia comunicativa en general omiten el componente intercultural. El MCER (2002) tampoco lo incluye en su estructura de la competencia comunicativa, aunque esto no significa que no lo reconozca. Dentro de las antes mencionadas competencias generales $^{3}$ del usuario de una lengua extranjera, los autores del MCER (2002) hablan de la "conciencia intercultural", "las habilidades interculturales" o "la personalidad intercultural". Generalmente se trata de relacionar y entender la propia cultura y la cultura extranjera, usar unas determinadas estrategias para establecer y mantener contacto con personas de otras culturas sin visiones estereotipadas.

Estas consideraciones nos han llevado a elaborar una propuesta de la competencia comunicativa que aparte de las competencias lingüística, sociolingüística y pragmática aborda también dos competencias de carácter intercultural (Fig. 1). Para ello, partimos de la base establecida por el MCER (2002) y las investigaciones realizadas en el campo de la comunicación intercultural (p. ej. Byram, 1997; Byram \& Fleming, 2001; Spychała, 2010, 2012, 2013; Wilczyńska, Mackiewicz, Krajka, 2019 y otros). También examinamos las bases teóricas que se refieren a las habilidades de un usuario competente de la lengua extranjera (Bardovi-Harlig, 1999; Pfeiffer, 2001; Komorowska, 2002; Wilczyńska, 2002).

\footnotetext{
${ }^{3}$ Consideramos que el componente intercultural debería formar parte integral de la competencia comunicativa del alumno. Estamos convencidas de que hay que desarrollar la competencia intercultural en la clase de una lengua extranjera junto con otras competencias lingüísticas y no esperar que el alumno llegue a clase disponiendo de una experiencia cultural previa y de una conciencia intercultural que, según el MCER (2002, p. 99), forma parte de sus competencias generales "menos relacionadas con la lengua".
} 


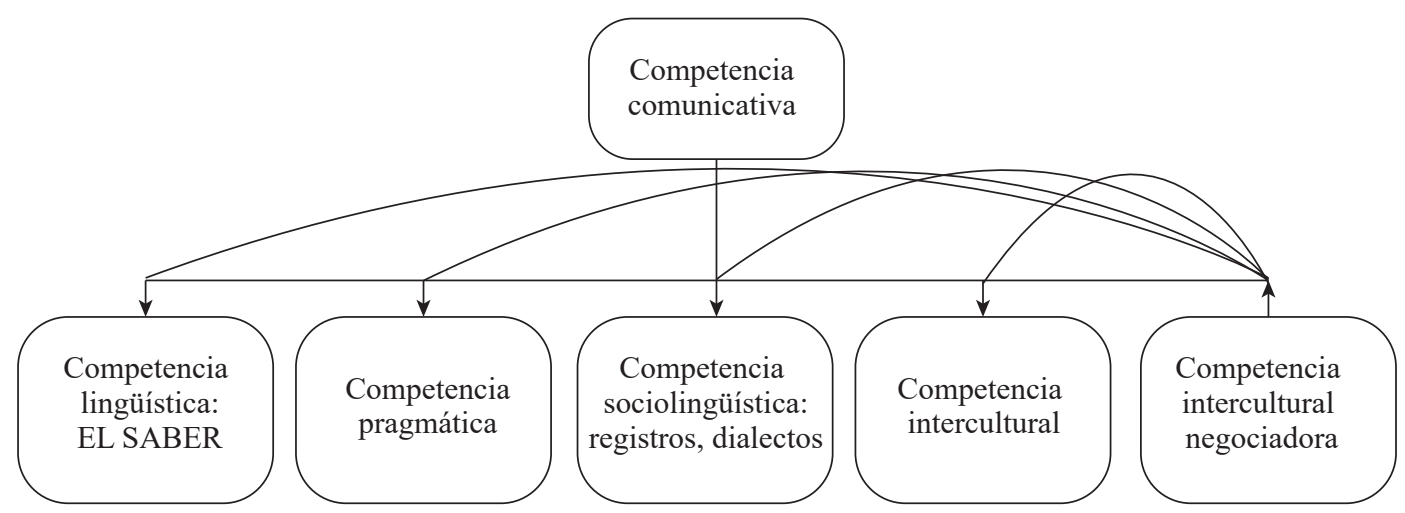

Fig. 1. El esquema de la competencia comunicativa (Spychała, 2013, 2015)

La competencia lingüistica comprende el uso apropiado de reglas gramaticales, la semántica, la ortografía, la pronunciación. La competencia sociolingüística se une con los conocimientos que se relacionan "específicamente con el uso de la lengua y que no se abordan en otra parte: los marcadores lingüísticos de relaciones sociales, las expresiones de la sabiduría popular, las diferencias de registro, el dialecto y el acento (MCER, 2002, p. 116). Y la competencia pragmática se basa sobre todo en el uso apropiado del discurso incluyendo las reglas de conversación oral. En cambio, las competencias interculturales hacen referencia a la comprensión de varias culturas (incluyendo la propia) y saber cómo actuar y negociar los significados (lingüísticos y culturales) dentro de un contexto cultural nuevo.

\section{LA COMPETENCIA PRAGMÁTICA Y LA COMPETENCIA INTERCULTURAL: ¿DOS CONCEPTOS PARALELOS?}

Los cambios sociales y las demandas actuales de la enseñanza de lenguas han colocado las dos competencias -pragmática e intercultural-en el punto de mira de los investigadores y docentes. Se trata sobre todo de desarrollar y promover la autonomía lingüística del estudiante dentro de cualquier entorno cultural nuevo para él.

Las investigaciones sobre la competencia pragmática, iniciadas en los años sesenta con los trabajos de Austin (1962) o Searle (1969)4, todavía se están revisando y actualizando. Reyes (1994) recuerda que "la pragmática empieza como un intento de encontrar el sentido de la conducta lingüística" (p. 15). Es una disciplina que estudia cómo los hablantes producen significados intencionales y cómo sus interlocutores in-

${ }^{4}$ Austin (1962) y Searle (1969) son unos de los más destacados representantes de la teoría de los actos de habla que hoy en día son estudiados por una parte bastante importante de la pragmática (Véase Spychała-Wawrzyniak, 2017). 
terpretan sus enunciados en unos determinados contextos. Por ejemplo: "Marido y mujer están en una fiesta; en cierto momento, ella le dice a él: ¿Tú sabes qué hora es? El marido interpreta automáticamente que su mujer quiere irse a casa, y le contesta algo como Nos vamos cuando quieras, en lugar de decirle la hora” (Reyes, 1994, p. 28).

La pragmática, por ende, se ocupa en gran medida de elementos extralingüísticos que influyen en el uso de las expresiones lingüísticas (Escandell Vidal, 1993). Una de las evidencias que lo confirman es la cortesía ${ }^{5}$, que se refiere a las normas sociales y conductas lingüísticas que funcionan en cada sociedad. Entre los ejemplos podemos enumerar el distinto uso de los tratamientos pronominales (tú, vos, usted, vosotros) en los países hispanohablantes o las diferencias en las prácticas comunicativas interculturales de saludar, prometer, rechazar, disculparse, felicitar, agradecer, etc. “Así, un enunciado como ¿Puede usted decirme la hora? podría suscitar rechazo y resultar descortés a un interlocutor tailandés, que puede interpretar que se cuestiona su capacidad de llevar a cabo una acción muy simple" (Amorós Negre, 2014, p. 18).

¿Es posible entonces hablar en clase de ELE de todos estos factores, teniendo en cuenta la gran extensión geográfica y la variedad peninsular e hispanoamericana de la lengua española? Sin duda, el desconocimiento de rutinas lingüísticas y sociales puede llevar a los fracasos comunicativos, por eso, estamos de acuerdo con Vande Casteelle \& Escandell Vidal (2017) en que el usuario de lenguas debe ser pragmáticamente competente, es decir, sabe "utilizar la lengua de manera adecuada en distintos contextos y situaciones comunicativas" (p. 114). No obstante, el mayor problema que se nos presenta en el aprendizaje de una lengua extranjera y especialmente del español es la ya mencionada multitud de variantes lingüísticas y sociales con las que puede encontrarse un alumno. Está claro que tanto el profesor como el manual pueden disponer de un corpus de contenidos funcionales básicos que incluye los rasgos más generales de la lengua española tanto en España como en Hispanoamérica. Sin embargo, este material no podrá ayudar mucho al alumno a la hora de hablar con un nativo de español, ya que este normalmente no controla su acento, su forma de vocalizar las palabras o la velocidad de su habla sin mencionar el variado uso de americanismos ${ }^{6}$. Por eso, creemos que en este tipo de situaciones es constatable un reconocimiento y el desarrollo de las competencias interculturales.

Básicamente la competencia intercultural es el entendimiento mutuo de dos culturas $^{7}$ : la propia y la ajena. Según Byram $(1995,1997)^{8}$, la competencia intercultural

\footnotetext{
${ }^{5}$ Gutiérrez Ordoñez (2002) explica que "la cortesía es una institución cultural que tiende a establecer y mantener las buenas, relaciones sociales" (p. 71).

${ }^{6}$ Los americanismos serían las palabras propias de español de América. "El español de América no es una variedad de la lengua, sino un conjunto de variedades diferentes entre sí y con una personalidad bien marcada y forjada a golpes de historia y geografía” (Moreno Fernández, 2010, p. 48).

${ }^{7}$ En caso de encuentro realizado entre varias culturas podemos también hablar de un enfoque transcultural (Risager, 1998).

${ }^{8}$ Michael Byram (1997) es uno de los primeros autores que más ha influido en el desarrollo del concepto de la competencia intercultural en la didáctica de lenguas extranjeras. Basándose en la visión
} 
incluye: conocimientos de las diferencias culturales y sociales (savoirs), habilidades de interpretar, relacionar e identificar acontecimientos y conflictos culturales (savoir comprendre), habilidades de descubrir y aprender nuevos elementos culturales ( $\mathrm{s} a$ voir apprendre/faire), conciencia cultural crítica (savoir s'engager) y las actitudes de apertura y curiosidad que al mismo tiempo rechazan las posturas etnocéntricas. En otras palabras, la competencia intercultural se compone de: los saberes acerca de otra cultura, las habilidades de análisis de las diferencias y búsqueda de los nuevos conocimientos culturales, y las actitudes que ayudan a desenvolverse de manera apropiada (respetuosa) durante un encuentro (un viaje, el trabajo, etc.) intercultural (Spychała, 2009, 2015).

Por otra parte, la competencia intercultural negociadora permite al alumno ajustar los significados desconocidos para él en una situación concreta. Por eso, es importante fortalecer las capacidades conversacionales de los alumnos. Entre los mecanismos que se usan durante las negociaciones podemos enumerar las preguntas y las paráfrasis que ayudan en la comprensión, interpretación y clarificación de mensajes nuevos. A continuación prestamos un ejemplo de diálogo entre un nativo $(\mathrm{N})$ y un alumno (A) que aprende español:

1. N. - Hoy vamos a cenar una tortilla de patatas.

2. A. - ¿Una tortilla?

3. N. - Sí, es un plato típico de la cocina española hecho a base de patatas, huevos y cebolla.

4. A. - ¿Quieres decir que esto es como algo como huevos revueltos, pero con patatas?

5. N. - Sí, algo parecido.

Cuando el alumno carece de cualquier tipo de información tanto lingüística como cultural, al emplear las preguntas o paráfrasis pide la explicación de una palabra desconocida o verifica si ha entendido bien el mensaje. Esto nos lleva a la conclusión de que existe una necesidad de dar, dentro de la competencia comunicativa, la misma importancia tanto a los aspectos pragmáticos como a los interculturales mediante el desarrollo de las destrezas productivas y receptivas". Además, "todo el input destinado a contribuir al conocimiento pragmático del aprendiz debe consistir en material auténtico, de manera que refleje fielmente el comportamiento de hablantes y oyentes en la cultura meta" (Martín Leralta, 2009, p. 57).

\footnotetext{
de la competencia comunicativa de Gudykunts \& Young Yun (1984) y van Ek (1986), este autor une la competencia comunicativa con la competencia intercultural y construye un modelo de la competencia comunicativa intercultural compuesto de cuatro elementos: la competencia lingüística, la sociolingüística, la discursiva y la intercultural.

${ }^{9}$ En nuestro estudio también analizamos las actitudes de los alumnos de ELE hacia las cuatro destrezas lingüísticas: comprensión auditiva, expresión oral, expresión escrita y comprensión lectora.
} 


\section{LAS ACTITUDES PREVIAS DE LOS ESTUDIANTES POLACOS Y ALEMANES HACIA LA COMPETENCIA PRAGMÁTICA Y LA COMPETENCIA INTERCULTURAL}

El objetivo del presente estudio piloto se basa en examinar las actitudes de los estudiantes que aprenden español en el ambiente universitario hacia las competencias pragmática e intercultural. El análisis forma parte de una mayor investigación cuyo objetivo es verificar las actitudes de los alumnos hacia el aprendizaje de español individualizado y autónomo. Conviene subrayar que en la encuesta no ponemos preguntas relacionadas directamente con la competencia pragmática o intercultural, ya que por nuestra experiencia sabemos que los alumnos no reconocen, en su mayoría, estos conceptos. A partir de nuestro marco teórico formulamos la siguiente pregunta general de investigación: ¿Cuáles son las actitudes previas de los estudiantes polacos y alemanes hacia las competencias pragmática e intercultural? La hipótesis general que nos planteamos es que en la clase de español en la universidad no se da tanta importancia al desarrollo de las competencias pragmática e intercultural en comparación con otros componentes de la competencia comunicativa.

En total, investigamos las respuestas de 101 participantes (41 alemanes y 60 polacos $)^{10}$. Los estudiantes alemanes pertenecen a las facultades de Ciencias Culturales, Ambientales y Empresariales de la Universidad Leuphana de Lüneburg. Dichos alumnos aprenden español como curso adicional de lengua extranjera. En cambio, los polacos de la Universidad Adam Mickiewicz de Poznań son estudiantes de filología española en diferentes cursos: primero (49\%), segundo (18\%) y cuarto $(33 \%)$. En cuanto a los datos sociodemográficos, contamos con 5 hombres (12\%) y 36 mujeres (88\%) en el grupo alemán. Entre los estudiantes polacos hay 10 hombres (17\%) y 40 mujeres $(83 \%)$. Según los datos, la muestra en su totalidad (véase tabla 1) se caracteriza por estudiantes de una edad similar entre $19-25$ años $(87,1 \%)$.

Tabla 1. Frecuencias de la variable edad de los encuestados

\begin{tabular}{|l|c|c|c|c|}
\hline \multirow{2}{*}{ Edad } & \multicolumn{2}{|c|}{ Estudiantes polacos } & \multicolumn{2}{c|}{ Estudiantes alemanes } \\
\cline { 2 - 5 } & Frecuencia & Porcentaje & Frecuencia & Porcentaje \\
\hline $19-25$ años & 46 & $77 \%$ & 39 & $96 \%$ \\
\hline 26-30 años & 6 & $10 \%$ & 1 & $2 \%$ \\
\hline $31-45$ años & 7 & $11 \%$ & 0 & $0 \%$ \\
\hline 46-60 años & 1 & $2 \%$ & 1 & $2 \%$ \\
\hline TOTAL & $\mathrm{n}=60$ & $100 \%$ & $\mathrm{n}=41$ & $100 \%$ \\
\hline
\end{tabular}

${ }^{10} \mathrm{El}$ estudio fue realizado en marzo de 2020 y por razones relacionadas con la pandemia no conseguimos realizar más encuestas entre los estudiantes alemanes. 
El nivel de español de todos los encuestados oscila entre B1 y C1 y en cuanto a la cantidad de tiempo dedicado al español (Tabla 2), más de la mitad $(52,4 \%)$ de ellos ha declarado que lleva estudiando español entre 2 y 5 años.

Tabla 2. Cantidad de tiempo estudiando español por parte de los encuestados

\begin{tabular}{|l|c|c|c|c|}
\hline & \multicolumn{2}{|c|}{ Estudiantes polacos } & \multicolumn{2}{c|}{ Estudiantes alemanes } \\
\hline Cantidad de tiempo estudiando español & Frecuencia & Porcentaje & Frecuencia & Porcentaje \\
\hline $0-1$ años & 5 & $8 \%$ & 1 & $2,4 \%$ \\
\hline $2-5$ años & 30 & $50 \%$ & 23 & $56,2 \%$ \\
\hline $6-10$ años & 21 & $35 \%$ & 16 & $39 \%$ \\
\hline más de 10 años & 4 & $7 \%$ & 1 & $2,4 \%$ \\
\hline TOTAL & $\mathrm{n}=60$ & $100 \%$ & $\mathrm{n}=41$ & $100 \%$ \\
\hline
\end{tabular}

La mitad de los universitarios declaró también que está trabajando; sin embargo, solo el $18 \%$ ha elegido español por razones laborales. La fascinación por la lengua española $(67 \%)$ constituye la razón primordial que ha motivado a los encuestados a aprender español (tabla 3).

Tabla 3. Motivos para estudiar español como lengua extranjera en relación con la ocupación laboral

\begin{tabular}{|c|c|c|c|c|c|c|}
\hline \multirow{2}{*}{ ¿Trabaja usted? } & \multicolumn{3}{|c|}{ Estudiantes polacos } & \multirow{2}{*}{$\begin{array}{c}\text { Estu- } \\
\text { diantes } \\
\text { alemanes }\end{array}$} & \multirow{2}{*}{$\begin{array}{c}\text { Frecuencia } \\
\text { total }\end{array}$} & \multirow{2}{*}{$\begin{array}{c}\text { Porcentaje } \\
\text { total }\end{array}$} \\
\hline & I curso & II curso & IV curso & & & \\
\hline No & 22 & 6 & 3 & 20 & 51 & $50 \%$ \\
\hline Sí & 7 & 5 & 17 & 21 & 50 & $50 \%$ \\
\hline \multicolumn{7}{|l|}{$\begin{array}{l}\text { ¿Qué le hizo elegir } \\
\text { aprender español? }\end{array}$} \\
\hline futuro trabajo & 9 & 4 & 5 & 2 & 20 & $18 \%$ \\
\hline $\begin{array}{l}\text { fascinación por la } \\
\text { lengua extranjera }\end{array}$ & 21 & 10 & 15 & 28 & 74 & $67 \%$ \\
\hline futuros viajes & 1 & 0 & 0 & 3 & 4 & $12 \%$ \\
\hline Otros & 2 & 0 & 3 & 8 & 13 & $3 \%$ \\
\hline
\end{tabular}

No obstante, preguntamos también de qué manera quieren aprovechar el conocimiento de español en su futuro trabajo. Como se puede ver en la tabla 4, la categoría empresa internacional $(35 \%)$ es la que prevalece en las respuestas. Le siguen las categorías traductor, intérprete $(20 \%)$ y profesor de ELE (18\%). Es notable señalar que los estudiantes alemanes eligieron en menor medida la opción de trabajar como profesor de ELE en el futuro, ya que no estudian este tipo de carrera. 
Tabla 4. El conocimiento del español y los planes laborales

\begin{tabular}{|c|c|c|c|c|c|c|}
\hline \multirow{2}{*}{$\begin{array}{l}\text { Manera de aprovechar el } \\
\text { conocimiento de español } \\
\text { en su futuro trabajo }\end{array}$} & \multicolumn{3}{|c|}{ Estudiantes polacos } & \multirow{2}{*}{$\begin{array}{l}\text { Los estu- } \\
\text { diantes } \\
\text { alemanes }\end{array}$} & \multirow{2}{*}{$\begin{array}{l}\text { Frecuen- } \\
\text { cia }\end{array}$} & \multirow{2}{*}{$\begin{array}{c}\text { Porcen- } \\
\text { taje }\end{array}$} \\
\hline & I curso & II curso & IV curso & & & \\
\hline Una empresa internacional & 14 & 4 & 7 & 30 & 55 & $35 \%$ \\
\hline Guía de turismo & 4 & 2 & 3 & 4 & 13 & $8 \%$ \\
\hline Traductor, Intérprete & 16 & 2 & 9 & 5 & 32 & $20 \%$ \\
\hline Profesor de ELE & 7 & 9 & 11 & 1 & 28 & $18 \%$ \\
\hline Otra & 7 & 0 & 2 & 22 & 31 & $19 \%$ \\
\hline
\end{tabular}

Si analizamos las actitudes hacia los enfoques pragmáticos e interculturales, debemos subrayar que la mayoría de los estudiantes (89\%) admite que ha estado en alguna situación en la que ha utilizado el español fuera de la Universidad. En sus respuestas individuales, los estudiantes polacos declaran que han usado el español durante viajes, comprando cosas o respondiendo a preguntas sobre cómo ir a un sitio. Algunos, especialmente los del cuarto curso, han usado el español en su trabajo. Y los estudiantes alemanes, en su mayoría, señalaron que han vivido antes en un país hispanohablante o han viajado a España o a un país latinoamericano, lo que también confirman las respuestas a la pregunta sobre la estancia en un país hispanohablante: el 100\% de los estudiantes alemanes han admitido que han estado en varios países: España, Ecuador, Chile, Perú, México, etc. Aunque el $65 \%$ de los alumnos polacos han declarado que han viajado a un país hispanohablante, la mayoría ha estado solo en España (en Barcelona).

Es muy posible que estas experiencias tanto laborales como turísticas empujaran a los aprendices a otorgar la máxima importancia a dos destrezas: oral (47\%) y auditiva (36\%). En los siguientes puestos aparecen la destreza escrita (12\%) y la destreza lectora (5\%). En las preguntas abiertas los participantes opinan que hablar y escuchar son dos actividades comunicativas inseparables y juegan el papel primordial durante un encuentro intercultural (tabla 5).

Tabla 5. La importancia de las destrezas lingüísticas según los encuestados

\begin{tabular}{|c|c|c|c|c|c|c|}
\hline \multirow{2}{*}{$\begin{array}{l}\text { ¿Qué dos destrezas } \\
\text { lingüísticas son para us- } \\
\text { ted las más importantes? }\end{array}$} & \multicolumn{3}{|c|}{ Estudiantes polacos } & \multirow{2}{*}{$\begin{array}{c}\text { Estu- } \\
\text { diantes } \\
\text { alemanes }\end{array}$} & \multirow{2}{*}{$\begin{array}{l}\text { Frecuen- } \\
\text { cia }\end{array}$} & \multirow{2}{*}{$\begin{array}{c}\text { Porcen- } \\
\text { taje }\end{array}$} \\
\hline & $\begin{array}{c}\text { I } \\
\text { curso }\end{array}$ & $\begin{array}{c}\text { II } \\
\text { curso }\end{array}$ & IV curso & & & \\
\hline Comprensión lectora & 0 & 1 & 5 & 4 & 10 & $5 \%$ \\
\hline Expresión oral & 11 & 21 & 35 & 18 & 85 & $47 \%$ \\
\hline Expresión escrita & 2 & 3 & 10 & 6 & 21 & $12 \%$ \\
\hline Comprensión auditiva & 7 & 21 & 32 & 6 & 66 & $36 \%$ \\
\hline
\end{tabular}


Para que nuestro estudio sea más válido y fiable en cuanto a las actitudes hacia las competencias pragmática e intercultural, los estudiantes respondieron también a la siguiente pregunta: ¿Qué le falta en la clase de español? Hemos proporcionado varias opciones para elegir, incluyendo la de respuesta abierta. Utilizamos la escala de Likert de cinco valores: (1) no me falta nada, (2) me falta un poco, (3) me falta, (4) me falta bastante, (5) me falta mucho.

Tabla 6. Frecuencias de acciones educativas que faltan a los estudiantes polacos y alemanes en la clase de ELE

\begin{tabular}{|c|c|c|c|c|c|}
\hline & \multirow{2}{*}{ ¿Qué le falta en la clase de español? } & \multicolumn{2}{|c|}{$\begin{array}{l}\text { Estudiantes polacos } \\
\qquad(\mathrm{n}=\mathbf{6 0})\end{array}$} & \multicolumn{2}{|c|}{$\begin{array}{l}\text { Estudiantes alemanes } \\
\qquad(\mathrm{n}=\mathbf{4 1})\end{array}$} \\
\hline & & Media & $\begin{array}{l}\text { Desviación } \\
\text { típica }\end{array}$ & Media & $\begin{array}{l}\text { Desviación } \\
\text { típica }\end{array}$ \\
\hline 1. & Ejercicios gramaticales & 2,28 & 1,21 & 2,21 & 1,09 \\
\hline 2. & Escribir & 2,6 & 1,26 & 2,30 & 1,1 \\
\hline 3. & Escuchar audiciones & 3,0 & 1,34 & 2,36 & 1,05 \\
\hline 4. & Leer & 2,21 & 1,13 & 2,10 & 0,95 \\
\hline 5. & Conversar & 2,85 & 1,43 & 2,65 & 1,25 \\
\hline 6. & Hablar de las diferencias culturales & 3,16 & 1,25 & 2,26 & 1,20 \\
\hline 7. & $\begin{array}{l}\text { Hablar de las diferencias lingüísticas en la } \\
\text { lengua española entre España y los países } \\
\text { hispanoamericanos }\end{array}$ & $\underline{\mathbf{3 , 2 3}}$ & 1,34 & $\underline{2,81}$ & 1,13 \\
\hline 8. & $\begin{array}{l}\text { Desarrollar las habilidades de negociación } \\
\text { de los significados }\end{array}$ & 3,13 & 1,24 & 2,63 & 1,14 \\
\hline
\end{tabular}

Los resultados generalmente muestran pocas diferencias entre los estudiantes polacos y alemanes, aunque vemos que los alumnos polacos, en comparación con los alumnos alemanes, tienen más necesidad de hablar de las diferencias culturales en la clase de español: tal vez esto se deba a que no disponen de tantas posibilidades, como sus compañeros alemanes, de conocer sobre el terreno las culturas hispanohablantes. En cambio, los aprendices alemanes notan que les falta conversar en clase, en comparación con otras actividades (gramática, audición, lectura, escritura). Los valores de media (M) obtenidos revelan que la lectura, la gramática, la escritura y la destreza auditiva son las actividades que, en opinión de los informantes, son realizadas de manera bastante satisfactoria. No obstante, en los dos grupos la mayor valoración se da a las diferencias lingüísticas y culturales, lo que significa que según los estudiantes estas áreas deberían tratarse más en la clase de español. 


\section{CONCLUSIONES}

Con este estudio hemos pretendido sistematizar los actuales enfoques hacia dos componentes fundamentales de la competencia comunicativa en la enseñanza de lenguas extranjeras: el pragmático y el intercultural. Hemos centrado nuestra atención en la problemática observada en clase como consecuencia de la gran diversidad de contextos culturales donde se aprende español, resaltando la importancia de activar el desarrollo de las dos competencias en la clase de ELE y la necesidad de aprender a negociar los significados lingüísticos y culturales dentro de un contexto cultural diferente al de la lengua meta. Nuestra investigación ha confirmado que los estudiantes también consideran que se debería prestar mayor atención a las diferencias tanto lingüísticas como culturales entre los países hispanoamericanos. Los estudiantes universitarios, sobre todo los alemanes, valoran bastante la negociación de los significados. Podemos suponer que, debido a que la mayoría de ellos -a diferencia de los alumnos polacos- ha viajado o ha vivido en países hispanoamericanos, tiene más conciencia de los desafíos lingüísticos y culturales que se pueden encontrar en la lengua española. Por eso, declaran que la conversación y el saber negociar los significados desconocidos son las habilidades que se deberían desarrollar más en la clase de español.

Para cerrar estas conclusiones, queremos invitar a los profesores de ELE a introducir y practicar más los componentes pragmáticos e interculturales. Se trata de concienciar a sus alumnos acerca de las diferencias lingüísticas existentes en la lengua española y al mismo tiempo desarrollar las habilidades comunicativas que les ayudarán a actuar de manera apropiada en algunas situaciones culturalmente sorprendentes e inesperadas. 


\section{BIBLIOGRAFÍA}

Amorós Negre, C. (2014). Las lenguas en la sociedad. Madrid: Editorial Síntesis.

Austin, J. (1962, 1982). Cómo hacer cosas con palabras. Barcelona: Paidós.

Bachman, L. (2000). Habilidad lingüística comunicativa. In M. Llobera (Ed.), Competencia comunicativa. Documentos básicos en la enseñanza de lenguas extranjeras (pp. 105-128). Madrid: Edelsa.

Bardovi-Harlig, K. (1999). Exploring the Interlanguage of Interlanguage Pragmatics: A Research Agenda for Acquisitional Pragmatics. Language Learning, 49, 677-713.

Byram, M. (1995). Acquiring intercultural competence. A review of learning theories. In L. Sercu (Ed.), Intercultural competence, vol. I (pp. 53-67). Denmark: Aalborg University Press.

Byram, M. (1997). Teaching and Assessing Intercultural Communicative Competence. Clevedon: Multilingual Matters.

Byram, M., Fleming, M. (2001). Introducción. In M. Byram \& M. Fleming (Eds.), Perspectivas interculturales en el aprendizaje de idiomas. Enfoques a través del teatro y la etnografía (pp. 9-17). Madrid: Cambridge University Press.

Canale, M., Swain, M. (1980). Theoretical bases of communicative approaches to second language teaching and testing. Applied Linguistics, 1, 1-47.

Chomsky, N. (1957). Syntactic Structures. The Hague: Mouton.

Chomsky, N. (1965). Aspects of the Theory of Syntax. Cambridge: MIT Press.

Cots, J.M. (2000). Hacia una descripción pedagógica de la competencia pragmática de los hablantes nativos de la lengua inglesa. In M. Llobera (Ed.), Competencia comunicativa. Documentos básicos en la enseñanza de lenguas extranjeras (pp. 91-114). Madrid: Edelsa.

Council of Europe (2020). Common European Framework of Reference for Languages: Learning, teaching, assessment. Companion Volume. Strasbourg: Council of Europe. Recuperado de: https://rm.coe.int/common-european-framework-of-reference-for-languages-learning-teaching/16809ea0d4.

van Ek, J.A. (1986). Objectives for foreign language learning, vol. 1. Strasbourg: Council of Europe: Scope.

Escandell Vidal, M.V. (1993). Introducción a la pragmática. Barcelona: Antrophos.

Gudykunst, W., Young Yun, K. (1984). Communicating with strangers: an approach to intercultural communication. New York: Random House.

Gutiérrez Ordóñez, S. (2002). De pragmática y semántica. Madrid: Arco/Libros.

Hymes, D.H. (1972). On Communicative Competence. In J.B. Pride \& J. Holmes (Eds.), Sociolinguistics. Selected Readings (pp. 269-293). Harmondsworth: Penguin.

Komorowska, H. (2002). Metodyka nauczania języka obcego. Warszawa: Fraszka Edukacyjna.

Martín Leralta, S. (2009). Competencia estratégica para la comprensión auditiva en español como lengua extranjera. Madrid: Ministerio de Educación.

MCER = Consejo de Europa (2002 [2001]). Marco común europeo de referencia para las lenguas: aprendizaje, enseñanza, evaluación. Madrid: Secretaría General Técnica del MEC, Anaya e Instituto Cervantes. Recuperado de: https://cvc.cervantes.es/ensenanza/biblioteca_ele/marco/cvc_mer.pdf.

Moreno Fernádez, F. (2010). Las variedades de la lengua española y su enseñanza. Madrid: Arco/Libros. Moreno Fernández, F. (2012). Principios de sociolingüistica y sociología del lenguaje. Barcelona: Ariel. Pfeiffer, W. (2001). Nauka języków obcych. Od praktyki do praktyki. Poznań: Wagros.

Reyes, G. (1994). La pragmática lingüística. El estudio del uso del lenguaje. Barcelona: Montesinos.

Ricós Vidal, A. (2013). El español: origen y situación actual. In M. Aleza Izquierdo (Ed.), Normas y usos correctos en el español actual (pp. 27-55). Valencia: Tirant Humanidades. 
Risager, K. (1998). Language teaching and the process of European integration. In M. Byram \& M. Fleming (Eds.), Language learning in intercultural perspective: approaches through drama and ethnography (pp. 242-254). Cambridge: Cambridge University Press.

Searle, J. (1969). Speach Acts. An Essay in the Philosophy of Language. Cambridge: Cambridge Univeristy Press.

Spychała, M. (2009). La importancia de la competencia intercultural en la interpretación de las diferencias culturales en la enseñanza del español como lengua extranjera. Entrecruces. Estudios Hispánicos e Hispanoamericanos, 1, 143-157.

Spychała, M. (2010). Interkulturowa kompetencja negocjacyjna a rozwój sprawności komunikacyjnych na lekcji języka obcego. In M. Pawlak \& E. Waniek-Klimczak (Eds.), Mówienie w języku obcym sukcesy i porażki uczenia się i nauczania (pp. 357-366). Konin: Wydawnictwo Państwowej Wyższej Szkoły Zawodowej.

Spychała, M. (2012). Dyskurs edukacyjny a rozwój interkulturowej kompetencji negocjacyjnej podczas lekcji języka obcego na przykładzie języka hiszpańskiego. Neofilolog, 38 (1), 91-106. DOI: 10.14746/n.2012.38.1.7.

Spychała, M. (2013). Ewolucja struktury kompetencji komunikacyjnej: od kompetencji językowej do interkulturowej kompetencji negocjacyjnej. In J. Stańczyk \& J.E. Nowikiewicz (Eds.), Dydaktyka językowa a kompetencje ogólne (pp. 25-34). Bydgoszcz: Wydawnictwo Nauczycielskie Kolegium Języków Obcych w Bydgoszczy.

Spychała, M. (2015). El desarrollo de la competencia pragmática en la enseñanza de ELE desde una perspectiva intercultural. In E. Stala, S. Balches Arenas \& C. Tatoj (Eds.), Tendencias en la enseñanza de español LE. Perspectivas glotodidácticas y metodológicas contemporáneas (pp. 185-206). Kraków: Wydawnictwo Uniwersytetu Jagiellońskiego.

Spychała-Wawrzyniak, M. (2017). La organización discursiva de los actos de habla en la conversación y la negociación de los significados interculturales en la enseñanza de ELE. In A.L. Duffé Montalván (Ed.), Singularidad y novedad en los estudios sobre los actos de habla (pp. 53-76). Madrid: Síntesis.

Vande Casteele, A., Escandell-Vidal, M.V. (2017). La realización de actos de habla. Propuesta de actividad de aprendizaje experiencial y colaborativo. In A.L. Duffé Montalván (Ed.), Singularidad y novedad en los estudios sobre los actos de habla (pp. 113-122). Madrid: Síntesis.

Wilczyńska, W. (2002). Podmiotowość i autonomia jako wyznaczniki osobistej kompetencji komunikacyjnej. In W. Wilczyńska (Ed.), Autonomizacja w dydaktyce języków obcych. Doskonalenie się w komunikacji ustnej (pp. 51-67). Poznań: Wydawnictwo Naukowe UAM.

Wilczyńska, W., Mackiewicz, M., Krajka, J. (2019). Komunikacja interkulturowa. Wprowadzenie. Poznań: Wydawnictwo Naukowe UAM. 